\title{
Desarrollo y Validación de un Método Espectrofotométrico para Cuantificación de Claritromicina en Comprimidos
}

\author{
ANDREA CUMBA ${ }^{a *}$, CARLOS CALDERÓN ${ }^{a}$ \\ a Facultad de Ciencias Químicas, Universidad Central del Ecuador, Quito-Ecuador \\ *Correspondencia: andrea_cumba@centrocesal.com \\ Recibido: 15 enero 2010 / Aceptado: 20 enero 2011
}

\section{Resumen}

Se describe un método espectrofotométrico para la cuantificación de claritromicina en comprimidos, que se fundamenta en la formación de un compuesto cromóforo coloreado que resulta de la reacción entre claritromicina en solución y ácido sulfúrico concentrado y que absorbe en la región visible a $481 \mathrm{~nm}$. En esta longitud de onda, la claritromicina contenida en un producto terminado, presenta lecturas de absorbancia que son directamente proporcionales a la concentración. La evaluación de la trazabilidad de los resultados obtenidos con el método espectrofotométrico, se realizó por comparación con el método de referencia (Cromatografía HPLC USP 29), y estadísticamente, a través de una prueba de t pareada, que determinó la no existencia de diferencias significativas entre los resultados de ambos métodos, por lo que el método desarrollado es trazable. Finalmente, se validó el método espectrofotométrico, para garantizar coherencia y reproducibilidad en los resultados. Para esto se evaluaron los parámetros de especificidad, robustez, linealidad, exactitud, precisión expresada en sus dos formas: repetibilidad y reproducibilidad. El método analítico resultó ser específico para la claritromicina, lineal en el intervalo validado de $15-50$ ppm, el coeficiente de variación obtenido para la repetibilidad y reproducibilidad fue del $1 \%$ y el porcentaje de recuperación obtenido fue de $100.5 \%$.

Palabras clave: claritromicina, espectrometría visible, validación de métodos analíticos.

\section{Development and Validation of a Spectrophotometric Method for Quantification of Clarithromycin Tablets}

\begin{abstract}
We describe a spectrophotometric method for quantification of clarithromycin tablets, which is based on the formation of a colored chromophore compound resulting from the reaction between clarithromycin solution with concentrated sulfuric acid, this chromophore absorbs at $481 \mathrm{~nm}$. At this wavelength the clarithromycin-containing chromophore presents an absorbance that is directly related to its concentration.
\end{abstract}

The evaluation of the traceability of the results obtained with the spectrophotometric method was performed by comparison with the reference method (HPLC Chromatography USP 29) and statistically through a paired t test, which determined that there were no significant differences between the results of both methods indicating that the developed method is traceable. Finally, the spectrophotometric method was validated to ensure consistency and reproducibility of the results. The evaluated parameters were specificity, robustness, linearity, accuracy, pre- 
cision expressed in two ways: Repeatability and reproducibility. The analytical method proved to be specific for Clarithromycin, and linear in the range of $15-50 \mathrm{ppm}$. The variation coefficient obtained for repeatability and reproducibility was $1 \%$ and the percentage of recovery obtained was $100.5 \%$.

Key words: clarithromycin, visible spectroscopy, validation of analytical methods.

\section{Introducción}

La industria farmacéutica siempre se ha enfocado en investigar nuevos métodos analíticos, que permitan la obtención de resultados en forma rápida, reproducible y confiable, para un ensayo específico. Sin embargo, algunos nuevos métodos analíticos investigados para determinados principios activos quedan sin aplicación, debido a que sus parámetros de desempeño de calidad (linealidad, rango, precisión, exactitud, especificidad y robustez) y operativos (sencillez y economía) resultan ser no idóneos para un ensayo analítico específico. $Y$ aunque no pueda afirmarse que este sea el caso de claritromicina, por falta de información, únicamente puede mencionarse que no se conocen investigaciones sobre nuevos métodos analíticos para este principio activo.

Actualmente, la industria farmacéutica dispone de un solo método analítico para la cuantificación de claritromicina en todas las formas farmacéuticas disponibles en el mercado, así lo evidencia, la información obtenida de una búsqueda realizada en documentos oficiales y no oficiales. El método de Cromatografía Líquida de Alta Resolución HPLC, es el único descrito en la farmacopea de los Estados Unidos USP 29 [1]. Al no existir alternativas analíticas para cuantificar claritromicina, se generan algunas limitaciones, entre ellas: congestiones por el elevado número de ensayos en los laboratorios de control de calidad, interrupciones por mantenimiento correctivo y preventivo del cromatógrafo, laboriosidad del método, altos costos de operación y finalmente dificultades técnicas.

No se conocen estudios acerca del desarrollo de nuevos métodos analíticos para claritromicina. El nuevo método espectrofotométrico que se desarrolló, se fundamentó en una reacción de hidrólisis del principio activo con ácido sulfúrico y formar un compuesto coloreado que absorbe en la zona visible del espectro [2].
El propósito de este estudio, fue desarrollar un método espectrofométrico reproducible y confiable para la cuantificación de claritromicina en comprimidos.

\section{Materiales y Métodos}

\subsection{Reactivos}

- Metanol grado HPLC

- Estándar de claritromicina USP

- Ácido clorhídrico $0.1 \mathrm{M}$

- Buffer de acetato de sodio 0.1 M pH 5.0

- Agua analítica tipo II

\subsection{Equipos}

- Cromatógrafo líquido de alta resolución HPLC, con detector UV-Vis (SHIMADZU)

- Espectrofotómetro UV-Vis (SHIMADZU 1800 UV-Vis)

- Purificador de agua (ELGA CLASSIC)

- Potenciómetro (Ph/ION 125)

- Balanza Analítica (Mettler Toledo AG204)

\subsection{Muestras}

Los comprimidos de claritromicina se obtuvieron de tres casas farmacéuticas en las que la concentración del activo es declarada.

\subsection{Establecimiento de los parámetros del método espectrofotométrico (optimización del método)}

La velocidad de la reacción es indicada por la velocidad de desarrollo del color, la cual depende, a su vez, de la velocidad de ataque del reactivo cromóforo a claritromicina.

Para optimizar el desarrollo del color y conforme a ley de Beer, se ensayaron variables tales como: solu- 
bilidad de claritromicina, ionización de la molécula, volumen de reactivo cromóforo y tiempo de reacción en el que se alcanza el máximo color [3].

Se probó la solubilidad de claritromicina en diferentes solventes [4]. El solvente escogido fue una solución buffer de acetato de sodio $0.1 \mathrm{M}$; la bibliografía reporta que el pH ácido es indispensable para la ionización de la molécula, por lo que se utilizó una solución de $\mathrm{HCl} 0.1 \mathrm{M}$ para llevar a $\mathrm{pH} 4.5$; posteriormente se agregó un volumen de ácido sulfúrico concentrado y se observó el desarrollo de un color intenso alrededor de 75 minutos (tiempo en el que se desarrolla todo el color) y posteriormente, se realizó un barrido espectral en la zona visible del espectro y el pico máximo de absorción se obtuvo a los $481 \mathrm{~nm}$. El mismo procedimiento se realizó para claritromicina contenida en comprimidos para probar la existencia de interferencias por matriz en la reacción.

\subsection{Determinación cuantitativa por HPLC- Determi- nación de la trazabilidad del método}

Utilizando un cromatógrafo líquido HPLC, una columna cromatográfica RP-C18 4mm * $15 \mathrm{~mm}$, la temperatura de columna de $45^{\circ} \mathrm{C}$, flujo de $1 \mathrm{~mL} / \mathrm{min}$ y con un detector a $210 \mathrm{~nm}$ se cuantificó el contenido de claritromicina en comprimidos de tres casas farmacéuticas y se procesaron los datos, obteniéndose lecturas de absorbancia que son directamente proporcionales a la concentración.

\subsection{Determinación cuantitativa por Espectrofotome- tría-Determinación de la trazabilidad del método}

Utilizando un espectrofotómetro y realizando la reacción de coloración de la claritromicina con ácido sulfúrico, se cuantificó el contenido en comprimidos de tres casas farmacéuticas y se procesaron los datos, obteniéndose lecturas de absorbancia que son directamente proporcionales a la concentración.

\subsection{Preparación de la curva de calibración [5]}

Se trabajó con soluciones estándar de claritromicina, se pesó $300,400,500,600,700 \mathrm{mg}$ de principio activo para los niveles de $15,20,25,30$ y 35 ppm respectivamente, en un balón de $1000 \mathrm{~mL}$, se agregó $500 \mathrm{~mL}$ de Buffer Acetato de Sodio 0.1 My se zonificó por 10 $\min$. Se tomó $5 \mathrm{~mL}$ de la solución anterior y se agregó el volumen de ácido sulfúrico en que se desarrolló el color, se dejó reaccionar por 75 min y se aforó con solución de $\mathrm{HCl}$ y se leyó la absorbancia a $481 \mathrm{~nm}$.

\subsection{Preparación de la muestra}

Diez comprimidos de cada casa comercial se trituraron hasta polvo y se pesó la cantidad equivalente para llegar a concentraciones de 15, 25, 35, 55 ppm. Las muestras se trataron de la misma manera que los estándares.

\subsection{Determinación de trazabilidad del método [6]}

Para comparar la trazabilidad del método espectrofotométrico se realizó una t pareada con los datos de cuantificación de claritromicina en comprimidos, obtenidos por los dos métodos y se determinó que no existe diferencias significativas.

\subsection{Validación del método analítico}

Se establecieron los criterios de aceptación para cada parámetro de calidad de la validación del método y se procedió a realizar los ensayos de linealidad, precisión, exactitud, robustez e incertidumbre $[7,8]$.

Para la linealidad, se realizó un ajuste, cada día y por cinco días de la función de respuesta instrumental para cinco niveles de concentración $(15,20,25,30$, $35 \mathrm{mg} /$ L) por triplicado en cada nivel.

La determinación de la exactitud, se realizó con un Material de Referencia (MR) [9] o material de Referencia enriquecido en 5 niveles $(15,25,35,55 \mathrm{mg} / \mathrm{L})$ y de un material de referencia certificado (MRc) por quintuplicado, en condiciones de repetibilidad. Repetición del diseño anterior en cinco días distintos en condiciones de reproducibilidad.

La determinación de la especificidad se realizó con muestras de 3 casas farmacéuticas por triplicado para la realización de un barrido espectral.

La determinación de la robustez, se realizó con un Material de Referencia (MR) en un nivel de concentración determinado por triplicado y variando el tiempo de reacción de la formación del cromóforo coloreado, el 
$\mathrm{pH}$ de la solución buffer acetato y la normalidad del ácido clorhídrico.

\section{Resultados y Discusión}

\subsection{Selección de la longitud de onda}

Se observó el valor de la longitud de onda en el que la claritromicina tiene un pico de absorción máxima en la región del visible, cuando se solubiliza en buffer acetato de sodio y se agrega diferentes volúmenes de ácido sulfúrico concentrado para evaluar el desarrollo máximo de color. Además se obtiene la respuesta del principio activo puro y de una muestra para evaluar las interferencias.

Tabla 1. Pico de absorción máxima Uv-Vis

\begin{tabular}{lcccc}
\hline Solventes & $\begin{array}{c}\text { Volumen } \\
\text { Reactivo, } \\
\text { ml }\end{array}$ & $\boldsymbol{\lambda}$ & Abs. st & Abs. M \\
\hline B. Acetato Sodio/ A. sulfúrico & 10 & 481 & 0.604 & 0.610 \\
B. Acetato Sodio/ A. sulfúrico & 7.5 & 481 & 0.201 & 0.147 \\
B. Acetato Sodio/ A. sulfúrico & 5.0 & 481 & 0.158 & 0.060 \\
B. Acetato Sodio/ A. sulfúrico & 2.5 & 481 & 0.098 & 0.0054 \\
\hline
\end{tabular}

\subsection{Intervalo óptimo de concentraciones y curva de calibración.}

El gráfico 1 representa la relación entre la absorbancia y la concentración de claritromicina, cuando se cambia el volumen de ácido sulfúrico concentrado (reactivo que desarrolla color). Además se indica el valor del grado de correlación $\mathrm{R}^{2}$, que es un parámetro que evalúa la linealidad.

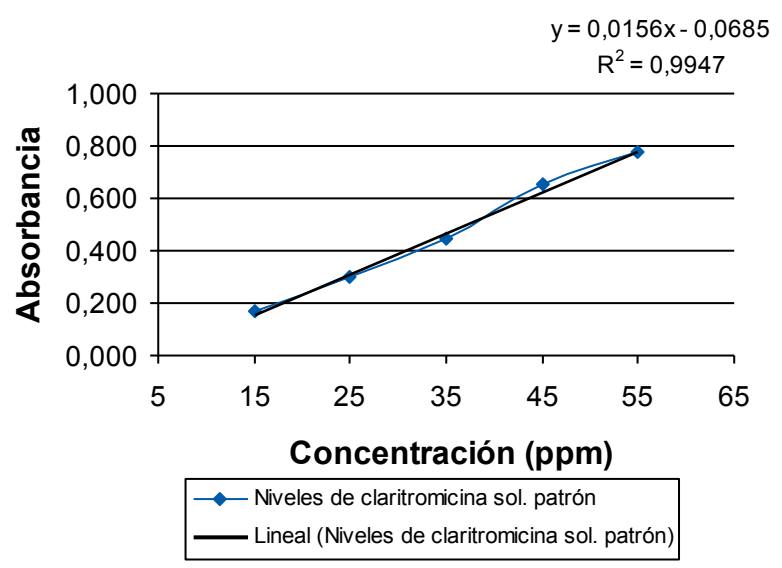

Gráfico 1. Intervalo óptimo de concentraciones para claritromicina (reacción con $10.0 \mathrm{~mL}$ ácido sulfúrico)
El valor del grado de correlación $R^{2}$ es 0.9947 .

\subsection{Comparación del método cromatográfico y espectrofotométrico para cuantificación de claritromicina}

\subsubsection{Método Cromatográfico [10]}

Se observan los valores de las áreas de los picos cromatográficos y los valores de concentración en (mg/tab) correspondientes al estándar y a los materiales de referencia de un lote piloto de claritromicina rechazado. El estándar se repite tres veces al inicio y dos al final del análisis, mientras que cada medida independiente de un material de referencia se repite dos veces durante el análisis, todo esto para evaluar la idoneidad del sistema.

Tabla 2. Valoración de claritromicina por método cromatográfico

\begin{tabular}{lcccc}
\hline & $\begin{array}{c}\text { Peso de } \\
\text { polvo }\end{array}$ & Áreas & $\begin{array}{c}\text { F } \\
\text { Conversión }\end{array}$ & Conc. \\
\cline { 2 - 5 } & (mg) & & & (mg/tab) \\
\hline Estándar 1.1 & ------ & 4,08346 & 62766,6 & 63,38 \\
Estándar 1.2 & ------ & 4,09918 & 62766,6 & 63,38 \\
Estándar 1.3 & ------ & 4,08899 & 62766,6 & 63,38 \\
M. Referencia 1.1 & 139,91 & 4,09391 & 62766,6 & 448,98 \\
M. Referencia 1.2 & 138,18 & 3,99580 & 62766,6 & 448,05 \\
M. Referencia 2.1 & 139,78 & 4,08883 & 62766,6 & 448,85 \\
M. Referencia 2.2 & 138,96 & 4,05721 & 62766,6 & 448,00 \\
M. Referencia 3.1 & 140,46 & 4,10188 & 62766,6 & 448,98 \\
M. Referencia 3.2 & 139,55 & 4,07778 & 62766,6 & 448,35 \\
Estándar 1.4 & ------ & 4,08736 & 62766,6 & 63,38 \\
\hline Estándar 1.5 & ------ & 4,08580 & 62766,6 & 63,38 \\
\hline
\end{tabular}

\subsubsection{Método Espectrofotométrico}

En la tabla 3 se observan los valores de absorbancia y los valores de concentración en ( $\mathrm{mg} / \mathrm{tab}$ ) correspondientes al estándar y a los materiales de referencia de un lote piloto de claritromicina rechazado, analizados por el método espectrofotométrico. 
Tabla 3. Valoración de claritromicina por método espectrofotométrico

\begin{tabular}{cccc}
\hline No. MR & $\begin{array}{c}\text { Pesos M. } \\
\text { referencia, mg }\end{array}$ & Abs. & $\begin{array}{c}\text { Conc. } \\
\text { (mg/tab) }\end{array}$ \\
\hline 1 & 945,5 & 0,269 & 449,364 \\
2 & 945,3 & 0,268 & 447,788 \\
3 & 945,6 & 0,270 & 450,986 \\
4 & 945,8 & 0,269 & 449,221 \\
5 & 945,6 & 0,268 & 447,646 \\
6 & 945,7 & 0,269 & 449,269 \\
\hline
\end{tabular}

\subsubsection{Prueba t pareada}

Se indican los valores de concentración de claritromicina $(\mathrm{mg} / \mathrm{tab})$ de seis repeticiones o tratamientos del material de referencia del mismo lote piloto rechazado de claritromicina analizados por el método cromatográfico HPLC y espectrofotométrico.

Tabla 4. Concentraciones de muestras de claritromicina de 500 mg cuantificados por método espectrofotométrico y HPLC.

\begin{tabular}{lcccccc}
\hline & \multicolumn{6}{c}{ Concentración mg Claritromicina/ tab } \\
\hline Tratamientos & Rep 1. & Rep. 2 & Rep 3 & Rep 4 & Rep 5 & Rep 6 \\
\hline HPLC (H2) & 448,98 & 448,05 & 448,85 & 448,00 & 448,98 & 448,35 \\
Espectro (H1) & 449,36 & 447,79 & 450,99 & 449,22 & 447,65 & 449,27 \\
\hline
\end{tabular}

\subsubsection{Establecimiento de diferencias significativas}

Se observa el valor de $t$ calculado y los valores de $t$ de tablas, con los que hace una comparación así: la † calculada es menor a la $t$ de tablas al $5 \%$, por lo tanto no es significativo y se acepta la hipótesis nula. Ambos métodos son iguales.

Tabla 5. Valor de t calculado y de tablas: valor obtenido de una tabla de $t$ student al $5 \%$ y al $1 \%$.

\begin{tabular}{lccc}
\hline & t calculado & \multicolumn{2}{c}{$\mathbf{t}$ tablas $^{*}$} \\
\hline significancia & & $5 \%$ & $1 \%$ \\
& 1,032 & 2,571 & 4,032 \\
\hline
\end{tabular}

\subsubsection{Criterios de aceptación de validación [11]}

Se detallan los criterios de aceptación para los parámetros de validación del método espectrofotométri- co visible. Si el método cumple con estos criterios de aceptación se declarará validado.

Tabla 6. Criterios de aceptación en la validación

\begin{tabular}{lc}
\hline \multicolumn{1}{c}{ PARÁMETRO } & $\begin{array}{c}\text { OBJETIVO } \\
\text { ESTABLECIDO }\end{array}$ \\
\hline Selectividad/Especificidad & No existen interferencias \\
Linealidad/ Función respuesta & $\mathrm{R}^{2} \geq 0.99$ \\
Límite de detección del método & A determinar \\
Límite de cuantificación del método & A determinar \\
Incertidumbre & $\% \mathrm{U}(\mathrm{K}=2) \leq 30 \%$ \\
Exactitud/ Recuperación & $100 \% \mathrm{R}+/-2 \mathrm{~s}$ \\
Intervalo de trabajo & $15-55 \mathrm{ppm}$ \\
Precisión Repetibilidad & $\% \mathrm{Cv} \leq 2.5 \%$ \\
Precisión Reproducibilidad & $\% \mathrm{Cv} \leq 2.5 \%$ \\
Robustez & $\% \mathrm{Cv}: \leq 2.5 \%$ \\
\hline
\end{tabular}

\subsubsection{Resultados de la validación}

Tabla 7. Resultados de validación

\begin{tabular}{lccc}
\hline \multicolumn{1}{c}{ Parámetro } & $\begin{array}{c}\text { Criterio } \\
\text { Aceptación }\end{array}$ & Resultado & Cumple \\
\hline Linealidad & $\mathrm{R}^{2}>0.990$ & 0.9999 & Sí \\
LDM & A determinar & $0.44806 \mathrm{ppm}$ & Sí \\
LCM & A determinar & $1.2200 \mathrm{pm}$ & Sí \\
Repetibilidad & $\% \mathrm{Cv}<2.5$ & 1.00 & Sí \\
Reproducibilidad & $\% \mathrm{Cv}<2.5$ & 1.00 & Sí \\
Exactitud & $100+4 \mathrm{~s}$ & 101.0 & Sí \\
Especificidad & Sin interferencias & Sin interferencias & Sí \\
Robustez & $\% \mathrm{Cv}<2.5$ & 0.40 & Sí \\
(Reacción de color) & & & \\
Incertidumbre & $\% \mathrm{U}(\mathrm{K}=2)=30 \%$ & 26 & Sí \\
\hline
\end{tabular}

\section{Conclusiones}

- En este estudio se desarrolló un método analítico espectrofotométrico, que resultó ser una alternativa analítica al método oficial HPLC para cuantificar claritromicina en comprimidos.

- La cantidad de claritromicina determinada por el método espectrofotométrico, se realizó por la formación de un cromóforo coloreado, que resultó de la reacción entre claritromicina (disuelta en buffer acetato de sodio y estabilizada a un $\mathrm{pH}$ de 4.5 con ácido clorhídrico) y $10.0 \mathrm{~mL}$ de ácido sulfúrico durante $75 \mathrm{~min}$ para desarrollar completamente el color; este 
compuesto tiene un pico máximo de absorción a los $481 \mathrm{~nm}$.

- El intervalo de concentraciones validado en que existe una relación lineal fue de 15 a 55 ppm.

- El límite de detección y el límite de cuantificación del método espectrofotométrico fueron de 0.44 ppm y 1.22 ppm, respectivamente.

- No existen diferencias significativas entre el método espectrofotométrico y el cromatográfico HPLC, ya que en la prueba de t pareada, se acepta la hipótesis nula, pues se obtuvo un valor de t calculado no significativo para $5 \%$ de $\dagger$ tablas.

- El método espectrofotométrico es selectivo o específico para claritromicina, pues en el estudio de muestras de tres casas comerciales no aparecen picos de absorción de interferentes en los barridos espectrales, lo que indica la no interferencia debida a excipientes.

- La curva de calibración o función respuesta instrumental resultó ser lineal, por el coeficiente de determinación que cumple con el criterio de aceptación mayor a 0.990 .

- El método espectrofotométrico es preciso, ya que los coeficientes de variación de las medidas de concentración de claritromicina en comprimidos, obtenidos en repetibilidad y reprodu- cibilidad fueron de $1.0 \%$, por tanto menores al criterio de aceptación establecido $(2.5 \%)$.

- El método espectrofotométrico es exacto, ya que los porcentajes recobrados de claritromicina en muestras enriquecidas fue de $100.5 \%$ y cumple el criterio de aceptación establecido de $100 \%+4$ sr.

- Los factores estudiados en la robustez no influyeron significativamente en los resultados, excepto el tiempo de reacción, por lo que las medidas de absorbancia deben realizarse hasta los 5 minutos luego de que se ha completado la reacción de formación del cromóforo, y las medidas obtenidas tienen un $\% \mathrm{CV}$ de $0.40 \%$.

- El valor de incertidumbre al $95 \%$ de confianza obtenido para este método analítico fue $26 \%$, por lo que cumple con el criterio de aceptación establecido, de modo que las fuentes que contribuyen a la medida de incertidumbre están controladas.

- Todos los parámetros de validación cumplen con los criterios de aceptación fijados. Por lo tanto, se declara al método espectrofotométrico validado y se garantiza la reproducibilidad y la confiabilidad de los resultados obtenidos por este método.

\section{Referencias}

1. USP United States Pharmacopeia Convention USP XXVII: United States Pharmacopoeia, Easton Marck Printing, 1990.

2. C. Avendaño, Introducción a la Química Farmacéutica, segunda edición, Mac Graw Hill, España 2001.

3. G. Almaraz, Nuevos Macrólidos superan a Eritromicina, Servicio de Farmacia hospital Valencia, 1995.

4. S. Budavari, The Index Merck, Eleventh Edition, Merck Research Laboratorios, Merck and Co. New Jersey.

5. W. Skoog, Química Analítica Instrumental, Edt Mac Graw Hill, Séptima edición, México, 2000.

6. G. Frederick, Principios de Garantía de Calidad para laboratorios analíticos, Association of Oficial Analytical Chemists, España, 1993.

7. B. Castillo, Protocolo de validación de métodos analíticos para la cuantificación de fármacos, Centro de Química Farmacéutica, Ave 200 y 21 Atabey, municipio Playa, Ciudad de La Habana, Cuba 2001.

8. Norma COGUANOR NGR/ISO 9000:2000 Sistemas de Gestión de Calidad Fundamentos y Vocabulario.

9. BIMP, IEC, IFCC, ISO, IUPAC, IUPAC, OIMIL, International Vocabulary of Basic and General Terms in Metrology (VIM: 1993) ISO.

10. H. Ludwing Good Laboratory Practice, Hewlett Packard, Germany, 1994.

11. ICH. Harmonised Tripartite Guideline Q2A Text on Validation of Analytical Procedures. International Conference on Harmonisation of Technical Requirements for Registration of Pharmaceuticals for Human Use. 1994. 